\title{
História e espacialidades faxinalenses: narrativas e representações imagéticas (1980 a 2015)
}

\author{
History and faxinalenses spatialities: narratives and imagetic representations \\ (1980 to 2015)
}

Historia y espacialidad faxinalense: representaciones narrativas y de imagen (1980-2015)

JoséAdilçon Campigoto

Ancelmo Schörner

\section{Resumo}

Neste artigo, discutimos a construção da espacialidade no âmbito da escrita da história dos povos tradicionais, especialmente os faxinalenses, tendo como fontes textos e representações pictóricas produzidas no âmbito acadêmico. Também discutimos fotografias de maquetes, desenhos e pinturas, de material produzido por alunos da educação básica de escolas da região de Irati/PR. O recorte temporal é de 1980 a 2015. Esses cenários de maquetes, textos acadêmicos e 'quadros' de mística (bem como os registros fotográficos) são produtos para o consumo. O croqui, o perfil esquemático e os textos acadêmicos aqui analisados são resultado de um consumo que, mesmo no interior das normatizações rígidas impostas pelo sistema de pro- dução científica, conseguem apresentar outra coisa, uma realidade modificada ou (re)significada frente aos discursos e aos processos de modernização agrícola.

Palavras-chave: Espacialidades. Faxinais. Imagens. Narrativas.
* Doutor em História pela Universidade Federal de San-
ta Catarina. Professor do Departamento de História e do
Programa de Pós-Graduação em História da Unicentro.
E-mail: jacampigoto@gmail.com
** Doutor em História pela Universidade Federal de San-
ta Catarina. Professor do Departamento de História e do
Programa de Pós-Graduação em História da Unicentro.
E-mail: ancelmo.schorner13@gmail.com

Recebido em 12/12/2016 - Aprovado em 02/3/2017 http://dx.doi.org/10.5335/hdtv.18n.1.6606 


\section{Introducão}

O tema proposto neste texto veio à tona a partir de um conjunto de questões e circunstâncias envolvendo jogos de escala, os faxinais, o espaço escolar, a temporalidade, a representação, o cotidiano, o narrador e as práticas de consumo. Trata-se de investigar a forma pela qual se elaboram as espacialidades e temporalidades faxinalenses em textos acadêmicos a respeito da história dos povos tradicionais. Também são cotejadas ilustrações feitas por pesquisadores e por alunos da Educação Básica tais como desenhos, pinturas e maquetes. Nesse caso, elas são o resultado de atividades didáticas desenvolvidas em dias letivos comuns, em semanas pedagógicas, em feiras de ciências ou em eventos similares ${ }^{1}$.

Sem desconsiderar a extraordinária variedade sociocultural e histórica brasileira, trataremos dos faxinais. Iniciamos por um texto de antropologia que, atualmente, embasa grande parte do material produzido a respeito dos povos tradicionais. Muito embora tenha vindo a público duas décadas depois da publicação dos primeiros estudos acadêmicos sobre os faxinais, servirá para abrir a discussão uma vez que também é contemporâneo à primeira tese de história dos faxinais. O escrito de Litlle estabelece um vínculo fundante entre sociedade, cultura e espaço, pressupondo que

A imensa diversidade sociocultural do Brasil é acompanhada de uma extraordinária diversidade fundiária. As múltiplas sociedades indígenas, cada uma delas com formas próprias de inter-relacionamento com seus respectivos ambientes geográficos, formam um dos núcleos mais importantes dessa diversidade, enquanto as centenas de remanescentes das comunidades dos quilombos, espalhadas por todo o território nacional, formam outro (2002, p. 2).
$\mathrm{O}$ autor vincula cultura e sociedade e regime de posse ou uso da terra, sendo que das relações estabelecidas entre esses três pólos resultaria uma vivência ou uma experiência de espacialidade. Desse modo, no Brasil, os povos indígenas formariam um núcleo desses ambientes geográficos, enquanto os remanescentes de quilombos representariam outro.

Nota-se que as categorias fundamentais envolvidas nessa discussão dizem respeito ao espaço, o que poderia representar uma resposta teórico-metodológica às dificuldades que encontramos para escrever a história dos povos de tradição oral. Na falta de documentos escritos, que possibilitariam uma amplificação da escrita na coordenada temporal, resvala-se para o aspecto da espacialidade. O texto de Paul Litlle é de antropologia, mas convém ressaltar que o conceito básico utilizado é território, o que fica evidente desde a segunda parte do título: por uma antropologia da territorialidade. Esse ferramental considerado como geográfico parece ter sido o que melhor se adaptou ao momento em que os povos tradicionais tornaram-se tema de interesse dos historiadores, bem como de pesquisadores de diversas outras áreas. A discussão tem a ver, principalmente, com o exercício do poder, pois,

Uma vez que um sistema jurídico funcione por algum tempo sobre uma certa extensão do espaço, este parece criar um momentum que lhe permite sobreviver a mudanças de regime político, pois a unidade da jurisdição territorial estabelece interesses comuns e um modus vivendi entre os habitantes, mesmo que eles pertençam a povos razoavelmente diversos. $\mathrm{O}$ território enquanto quadro para um sistema político separado é geralmente desejado para prover segurança física contra invasão ou controle estrangeiro (...) (GOTTMANN, 2012, p 528). 


\section{0 faxinal: indagações sobre 0 'antes tempo'}

O conceito de território parece fez jus ao que Gottmann (2012) denominou como era da soberania territorial e vinha sendo aplicado desde a década de 1980, com relativo sucesso, às investigações relacionadas aos povos faxinalenses. O sistema de faxinais implica certo modo de utilização coletiva dos recursos naturais a exemplo, das matas, das jazidas de pedras e argila, das pastagens comunais, bem como das aguadas. Uma das marcas mais caraterísticas dos faxinais, considerando-se a maioria dos textos publicados sobre o tema, é a descrição do espaço de uso coletivo, ambiente delimitado por um cercado comunitário, destinado à criação de animais.

Essa formatação conceitual, em termos da produção acadêmica sobre os faxinais, pode ser vinculada a um texto referência, mas da área do desenvolvimento rural, ou seja, nem da história, nem da geografia. Trata-se do Boletim técnico elaborado por Man Yu Chang e denominado Sistema Faxinal: uma forma de organização camponesa em desagregação no Centro-Sul do Paraná. Infere-se do próprio título tratar-se de um escrito pautado na ideia de segurança contra uma "invasão desagregadora" e uma "ameaça estrangeira desmanteladora". O texto, publicado no final da década de 1980, é exaltado como "[...] um dos pioneiros sobre o assunto dos faxinais e se constitui como referência para as pesquisas que vêm sendo realizadas sobre estes camponeses" (BARRETO, 2011, p. 249).
Na década de 1980, quando foi produzido, a chamada modernização da agricultura paranaense estava no auge. Priori apurou alguns indicadores numéricos das modificações na base técnica e produtiva desse setor da economia, ocorrida nos anos 1970 e 1980. Segundo ele:

[...] o número de tratores, por exemplo, sofreu uma alteração de $338,3 \%$ entre os anos de 1970 e 1980. Da mesma forma, houve elevação em outras atividades, como 'no número de arados de tração mecânica $(379,4 \%)$, no número de estabelecimentos com uso de força mecânica $(1.134,9 \%)$, no consumo de óleo diesel $(604,9 \%)$, no consumo de energia elétrica $(47,0 \%$ e $687,6 \%$ no período de 1980 a 1985) [...]. Mesmo no próprio Paraná o processo de modernização agrícola não ocorreu de forma homogênea, pois os efeitos desse processo foram sentidos de forma mais intensa no Norte e Oeste do Estado (2012, p. 22-23).

Algumas regiões, como a Centro Sul do Paraná, que foi alvo do estudo realizado por Chang, foram diagnosticadas como menos desenvolvidas, menos mecanizadas e mesmo em processo de esfacelamento, sendo classificadas como áreas afligidas por vários problemas sociais e com setores econômicos problemáticos. E, de forma geral, destacaram-se aspectos nefastos decorrentes de tal modernização ocorrida no Estado.

[...] O aumento do número e utilização de tratores, além de outros implementos e insumos agrícolas, eliminou muitos empregos no campo e engrossou as migrações para as cidades. Houve nesse momento, uma intensificação do êxodo rural, com uma população excluída se direcionando para cidades de maior porte na região [...] (PRIORI, 2012, p 123). 
Ocorre que, nessa mesma época, introduziram-se os tratores nos faxinais, e com eles, implementos e insumos agrícolas. Era como se plastificava o cenário do desmantelamento e da desagregação do espaço faxinalense, porque as alterações eram vistas como inusitadas e devastadoras. Pode-se mesmo incorporar a tese de que as décadas de 1970 e 1980 comportaram alterações significativas em termos da espacialidade rural: modificou-se a estrutura fundiária, isto é, os latifundiários ampliaram seu domínio territorial. Isso traduziu-se como "invasão desagregadora" e "ameaça desmanteladora" e representava o aumento da vulnerabilidade das pequenas e médias propriedades, um ataque aos modelos de agricultura não alinhados aos processos de modernização agrícola, e uma ofensiva às populações tradicionais da área rural do Paraná.

Esse clima de modificações, bem como de organização social, por certo, impactava programas como a proposta do Pro-Rural (Programa de Desenvolvimento Econômico e Territorial) e de modo mais indireto, a produção de estudos tais como o mencionado Boletim. Assim, pode-se perceber a configuração que a autora atribui aos faxinais: trata-se de algo próximo a uma das formas de organização que estavam a surgir naquele momento em todo o Estado. Mas esta do Centro Sul do Paraná, nem sempre estivera ali e já, um "espaço em estado de desagregação".

Conforme essa narrativa sobre os faxinais na década de 1980, a agricultura de subsistência praticada em função das fazendas paranaenses pelos agregados ${ }^{3}$ e camaradas desde o século XVIII entrara em declínio, na primeira metade do século XIX. Tal população deslocou-se dos Campos Gerais para a região Centro Sul e segundo Chang (1988) procurou outra região porque os capões de campos limpos não comportavam a ampliação desse tipo de economia. Encontraram ambiente favorável nas áreas de matas mistas.

Assim, pretende Chang (1988), deu-se a origem dos faxinais, consolidados a partir da chegada dos imigrantes eslavos, principalmente, os poloneses, costumados que eram acercar seus animais e a plantar suas lavouras em áreas abertas. Por influência deles, teriam surgido os criatórios comuns, considerados por muitos como a principal característica do sistema de faxinal. A tese de Chang é controversa e carente de base documental, e o argumento do "costume polonês" ${ }^{\prime 4}$ não se sustenta, uma vez que os caboclos ou os habitantes locais também cultivavam hábitos próprios e é difícil definir, em se tratando de gente da floresta, o que é cercar a lavoura ou os animais.

Podemos dizer que Chang "desespacialisou" o surgimento dos cercados comunitários nos faxinais, porque, num cenário de florestas, não faz muito sentido a oposição entre o regime de gado solto-roça cercada/roça aberta-gado preso. Nas áreas de campo onde predomina a pecuária, aí sim é mais lógico cercar as pequenas áreas plantadas que houver. Em áreas não cobertas por matas, quando predominam as plantações, então é mais econômico e viável criar o gado preso. O argumento de Chang é frágil, mas concordamos com a conjectura de que a entrada dos imigrantes provocou uma diminuição brutal das áreas cobertas por matas 
virgens e o aumento considerável de áreas com lavoura. Então, foi necessário cercar o gado, o que era a lei no Brasil desde 1850.

De qualquer modo, o estudo de Chang colocou em evidência o tema da espacialidade no âmbito dos estudos a respeito dos faxinais. $\mathrm{O}$ destaque à cerca coletiva - sob o rótulo de característica básica faxinalense - como que toma a função de divisor dessa espacialidade nas atividades acadêmicas e escolares em termos da história dos faxinais.

O primeiro texto historiográfico de âmbito acadêmico tratando dos faxinais é a tese de doutorado de Maria Magdalena Nerone (2000). Desde o título, destaca-se a imagem/conceito de que faxinal é um espaço dividido em duas áreas: as terras de plantar e as de criar. ${ }^{5}$ Desse modo, tendo a cerca coletiva como fronteira, divide-se a área em ambiente de compáscuo e lugar de plantio. Trata-se de um texto de história, mas a coordenada do espaço está em primeiro plano. Suspeitamos que em parte devido à escassez documental.

Nerone diz que a localidade de Marmeleiro de Baixo, sujeito do seu estudo, está situada no município de Rebouças-PR e menciona que a área correspondente às porções individuais (pode-se dizer igual ao cercado de responsabilidade individual) mediam 5.584 braças, algo em torno de 12.284 metros de cerca ou perímetro (NERONE, 2000, p. 18). No ano de 1991, quando foi lavrada a escritura pública relativa ao estabelecimento do criadouro comum do Marmeleiro de Baixo, a área total era de aproximadamente 580 hectares.

Após isso, passa à descrição detalhada de uma das moradias rurais existentes e em estilo descritivo, desloca-se para a espacialidade. Escreveu que no Faxinal Marmeleiro de Baixo, na década de 1990:

A moradia rural mais abastada era composta de várias construções: a casa grande, a cozinha de chão, o paiol (para guardar mantimentos, o milho, o feijão, e o arroz com casca), a casa de monjolo, a casa de forno, casa do carro (onde se guardavam a carroça, o arado, a carpideira (sic.), a grade, e os demais instrumentos de trabalhar na roça) a estrebaria e o galinheiro. Também fazia parte do conjunto o quintal, o jardim, o mangueirão, onde os porcos ficavam soltos (os porcos para engorda eram fechados no chiqueiro). Esses espaços eram contornados pela mangueira, uma cerca que geralmente era de frechame [...]. As casas eram, geralmente, de madeira (NERONE, 2000, p. 18).

O termo "casa grande" talvez seja, aqui, utilizado por inspiração de Gilberto Freyre, mas não se aplica no mesmo sentido que o sociólogo utilizou. No croqui de que se serviu para ilustrá-la não existe a "casa pequena" (ou a senzala) e nem mesmo outras casas de morada associadas a ela.

Pode-se dizer a partir da associação, inclusive, que o faxinal se apresenta como uma forma organizativa bastante diversa do modelo engenho exposto por Freyre. Não é comum, nos faxinais, haver um lugar, uma sede do poder e nem mesmo é usual destinar-se um lugar central para a igreja e a escola ou outras instituições. Melhor dizendo, os faxinalenses não organizam o espaço habitacional em função de um centro de poder e isso está, de certo modo, razoavelmente representado no referido croqui. Chang (1998) lembra sobre esse ponto que em determinadas épocas, especificamente na década de 
1950, o poder oficial nos faxinais foi regido pelos inspetores de quarteirão e municipais. Isso evidencia certa descentralização do poder o que se pode ver: a "casa grande", ou a habitação do faxinalense, nem é representada no centro, mas como parte de uma estrutura circular em relação às outras construções.

Figura 1: Croqui de casa faxinalense.

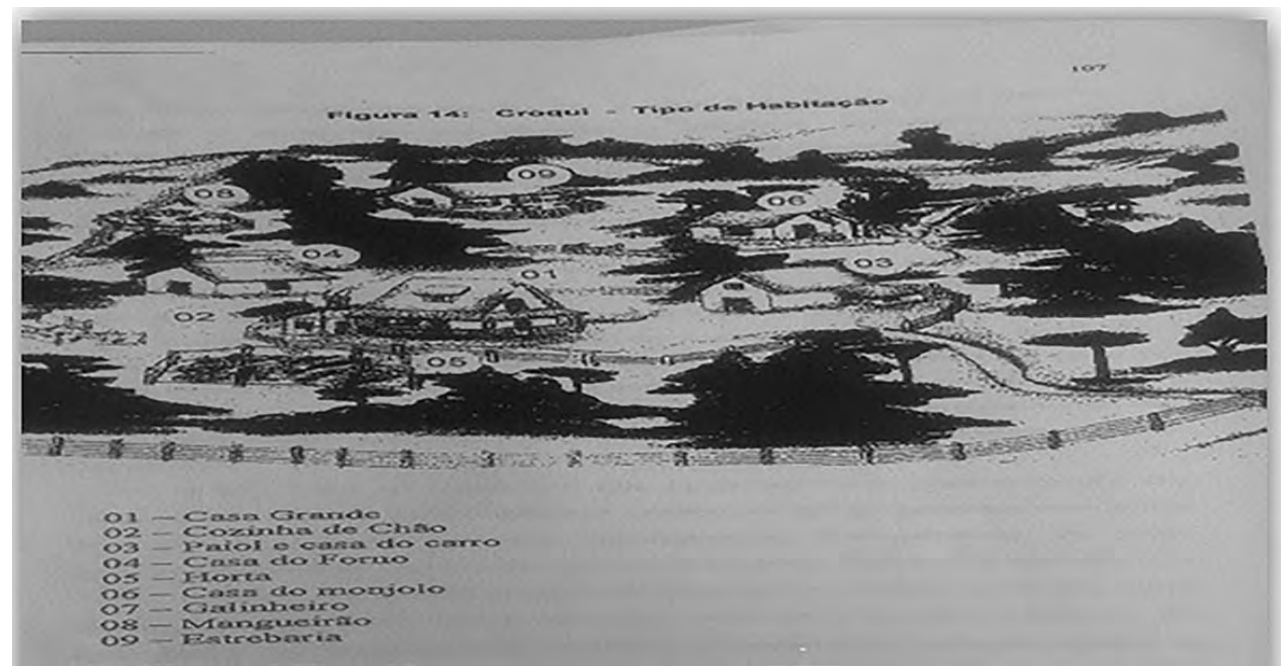

Fonte: Nerone (2000, p. 109).

Na produção do croqui, outro dado relevante aparece em primeiro plano: o cercado que contorna a área de compáscuo. A ilustração é de uma casa de faxinalense, o mais próspero do Marmeleiro no final da década de 1990, segundo a autora. No entanto, foi desenhada uma cerca que não faz parte da habitação. Trata-se do cercado coletivo e tanto é exótico ao tema que nem ao menos há legenda indicando-o. Se bem que talvez fizesse parte mesmo da paisagem, pois várias moradias são construídas nas proximidades dele. Também pode significar que este é o trecho de cercas pelo qual os moradores da casa representada devem responsabilizar-se.

Note-se, no entanto, que o componente em análise divide a tela em dois espaços: o primeiro deles, uma paisagem completamente limpa, contendo apenas legendas escritas. O segundo, depois da cerca, ostenta o criadouro comum, região repleta de elementos significativos como construções, pequenos cercados, caminhos, elevações, baixadas e árvores, destacando-se o pinheiro (em outras propostas aparece a erva mate). A cerca está ali como que a mostrar que se trata de um faxinal. Nesse caso, cumpre outra função que a de cercar a lavoura ou "fechar" o gado. Está, talvez, a indicar que esse elemento foi a peça fundamental para a consolidação do modelo organizacional faxinalense. Dito de modo simples, esse artefato está ali, entre o espectador e o objeto retratado, a sinalizar que o faxinal começa depois da cerca. Então, materializa o enunciado de que a construção 
da cerca comum conclui o processo de emergência dos faxinais na região Sul do Brasil.

Estabelecida a cerca no croqui, o espectador se situa na área de plantar, pois de outro modo, não poderíamos enxergá-la à frente do criadouro. Podemos acrescentar que, nesse caso, o efeito de separação que provoca é acentuado devido ao vazio projetado em primeiro plano. O faxinal emerge, assim, como um mundo separado, isolado, lançado para a distância, de modo a redizer a desagregação já anunciada. Desmantelamento, por se tratar de uma forma de organização camponesa desvinculada dos processos econômicos e mesmo geográficos circundantes. O espectador é levado a ver que nada existe fora do espaço delimitado por esta cerca/ redoma que está a envolver o lugar. Então, trata-se de uma forma organizativa em processo de desconexão, sem vínculos significativos com a cultura e a sociedade que lhe é exterior. Mas, ao mesmo tempo, indica uma realidade preservada em relação à lógica do espaço circunvizinho.

A impressão de sítio desconexo efetivamente se repete e reforça na função descritiva da "moradia mais abastada", adensando-se na exposição da "[...] casa do carro (onde se guardavam a carroça, o arado, a carpideira (sic.), a grade, e os demais instrumentos de trabalhar na roça) [...]" (NERONE, 2000, $\mathrm{p}$ 18). Nem a mais leve referência há na descrição, que se relativa a qualquer objeto típico da chamada modernização agrícola; apenas elementos da agricultura de subsistência. Nada referente à energia elétrica, também, no croqui, embora a representação seja da moradia mais próspera do Marmeleiro de Baixo, no final da década de 1990.
Do ponto de vista da espacialidade, o criadouro - representado pela casa situada no interior da área cercada - nos parece isolado pelo vazio que substituiu as terras de plantar. E convém acrescentar que esse primeiro plano não está para representar uma área desocupada de lavouras, pois, se assim fosse, seriam esboçadas as ondulações própria da geografia local que, aliás, aparecem claramente no restante do croqui. Mas levemos em consideração o dado de que não se trata de uma fotografia ou pintura, e, sim, de um croqui, um esboço esquemático com elementos básicos para se ter uma ideia do ambiente representado. Nele a cerca tem uma função específica.

Dissemos tratar-se de uma função discursiva na constituição da espacialidade faxinalense porque careou para o âmbito da academia a visão dual do espaço, que na esfera da historiografia se traduziu por meio da expressão "terras de plantar, terras de criar" e suas derivadas. Em que pese seu caráter de marco temporal (final do século XIX e início do XX), o enunciado da "cerca consolidante" ${ }^{\prime \prime}$ é central na constituição dessa espacialidade frequentemente reiterada na produção da história escrita dos faxinais.

É por essa linha narrativa, que vemos em Chang (1998), e que se repete, a nosso ver, no croqui publicado por Nerone (2000), os faxinais iniciariam, ou começariam a existir como entidade consolidada, somente depois da adoção de costume de cercar o gado pelos nativos. Em outras palavras: depois da cerca. No entanto, notamos que tal representação pode até contrapor-se à tese de Nerone porque, a área de plantio desapareceu no croqui. Insistimos, então, na importância 
do detalhe porque o corte poderia ser feito na cerca, sem que o vazio aparecesse. O corte na cerca vai aparecer em vários desenhos, fotos e pinturas que veremos adiante.

Vejamos que transcorrera uma década desde a produção do Boletim de Chang denunciando o processo de desagregação dos faxinais e surge a descrição de Nerone indicando outro enredo. Nele, o Marmeleiro do final da década de 1990 conta com uma casa mais abastada do que as outras, com paiol para armazenar milho, feijão e arroz, instrumentos de trabalho, carroça, arado e grade.

Ela recorreu a um personagem que, no passado, teria auxiliado o próprio pai a construir a primeira cerca coletiva para o estabelecimento do criadouro comum naquela localidade. Então, o marco narrativo na linha do tempo. Conforme a narrativa básica da análise feita por Nerone (2000, p. 99), o documento que simboliza a identidade do Marmeleiro é o registro do faxinal na câmara municipal de São João do Triunfo-PR. Mas esse não seria "o registro de nascimento da comunidade" . Tal registro dataria de 1928, porque, segundo a autora, a data representa "um elo de sentido", um marco referencial, indicando um antes e um depois, daquele momento que segundo as memórias locais, o povo se reuniu para criar o criadouro. Essa maneira de pensar os acontecimentos, fundamentada nas discussões empreendidas por Alfredo Bosi (1994, p. 21) apresenta-se, também, como "discurso fundador" ${ }^{\text {", do }}$ faxinal em questão.

Então, a autora apresenta a escrituração da área coletiva, ocorrida em 1991, como novo acontecimento fundante no desenvolvimento dessa história iniciada em 1928 (iní- cio das cercas). Ela afirma que o criadouro “(...) não nasceu do acaso, mas teve seu fundamento numa experiência ancestral" (NERONE, 2000, p. 102).

Tal ocorrência é narrada tendo como base os nomes dos proprietários de terra listados na escritura do faxinal, documento metaforizado por meio da Certidão de nascimento. Nesse caso, o Marmeleiro de Baixo teria sido fundado ou teria nascido duas vezes. Ao que parece, no entanto, a segunda vez foi significada como momento da regularização oficial. O fato é que o ano de 1991 é visto pela autora como marco de uma nova etapa dos faxinais: as normas de funcionamento do sistema foram escritas e registradas no cartório do município de Rebouças-PR. Então, este seria o acontecimento fundante: a normatização do faxinal, não havendo relação com a "cerca dos imigrantes", pois, no Marmeleiro, a presença desses é irrisória.

Já para o final da década de 1990, segundo Nerone (2000), eram 180 famílias, vivendo em 240 alqueires de terras. Ela relata que os donos dos animais criados em comum precisavam oferecer-lhes suplementação alimentar, sempre que necessário e, principalmente, nos períodos de maior escassez. Diz ainda que a administração da ração geralmente ocorria nas imediações das casas dos faxinalenses que eram dispostas no interior da área cercada, sendo boa parte delas protegida por um cercado menor, em torno das quais as criações circulavam livremente. Descreve as entradas e saídas dessas áreas, protegidas por porteiras e cancelas ou por uma espécie de pequena ponte, construída sobre vala escavada especialmente 
para tal fim. Condizente ao título, o trabalho de Nerone detalha a espacialidade do faxinal dividido em duas partes por meio do grande cercado: terras de plantar e terras de criar. Para nós, tal procedimento pode ter influenciado as produções posteriores especificamente na área da História e no campo das atividades didáticas desenvolvidas nas escolas de educação básica na região. Mas, principalmente, o texto de Nerone é uma apropriação, bem como as atividades escolares e em outros textos que analisaremos, o são.
Vários desses elementos reaparecem, grosso modo, numa imagem publicada pela geógrafa Cicilian Luiza Löwen Sahr nos Anais do $1^{\circ}$ Encontro dos povos dos faxinais realizado no ano de 2005 . Por conta do enfoque científico, destaca-se a espacialidade demarcada pelo cercado, assim como representou-se no croqui exposto por Nerone. Ressaltamos que haviam se passado cinco anos entre a utilização do croqui e a da imagem, e os faxinais haviam se tornado objeto de interesse para vários cientistas de diversas áreas do conhecimento.

Figura 2: Perfil esquemático das terras de faxinal.

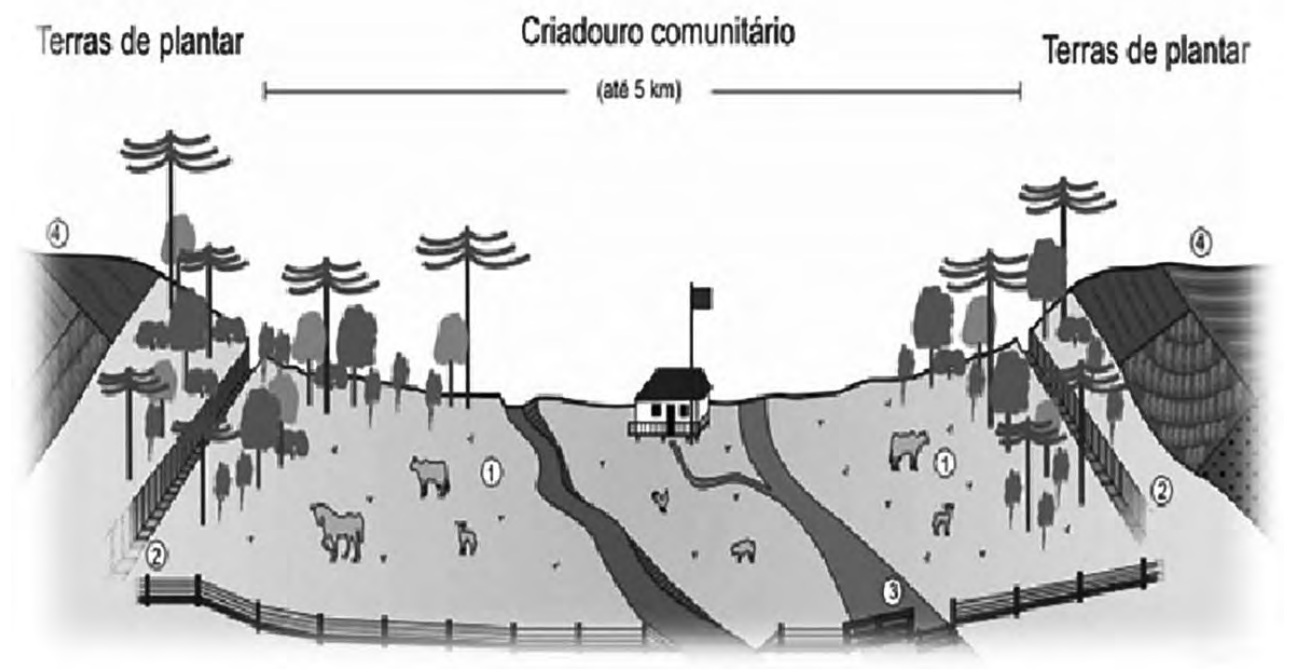

1 - Espaço do criadouro de uso comum (residências, pastagens, Mata com Araucária e criações). 2 - Limite entre o criadouro de uso comum e as terras de plantar (cercas e valos). 3 - Estradas que atravessam o criadouro (porteiras e mata-burros). 4 - Terras de plantar (milho e feijão).

Fonte: Löwen Sahr (2005, p. 58). 
O cercado separa somente o criadouro comum, pois a área de plantar situa-se ao lado, e não há espaço vazio separando o faxinal do espectador, mas esse se situa, também, fora da área do criadouro.

\section{Faxinal visto em maquetes, pinturas e desenhos}

Vários dos elementos vistos anteriormente se repetem nos trabalhos elaborados por alunos e professores(as) da educação básica ou quando confeccionados em conjunto. É bem possível que, na sala de aula, antes de apresentar qualquer proposta de atividade, seja realizada uma leitura ou uma exposição do tema. A aula teria por base, provavelmente, algum dos textos citados ou escritos neles fundamentados. As atividades de fixação e congêneres solicitadas pelas professoras e professores e aqui analisadas são de três tipos: maquetes, pinturas e desenhos.
Os trabalhos foram elaborados nos municípios de Rio Azul, Rebouças, Prudentópolis e Imbituva entre os anos de 2013 e 2016, e foram produzidos no âmbito da disciplina de História, ou para eventos desenvolvidos neste nível educacional, como a Feira das Idéias e a Feira das Ciências.

$\mathrm{O}$ primeiro destaque desse conjunto de fontes produzidas no desenvolvimento do projeto Obeduc (Observatório de Educação do Lapef), A escola e o ensino de história na região dos faxinais ${ }^{8}$ diz respeito às maquetes. Consideremo-las como representações tridimensionais, portanto, triplamente referentes ao espaço e que exigem muito mais tempo para serem elaboradas do que um desenho ou pintura. Essas, por nós fotografadas, foram montadas, visando-se a apresentações em eventos especiaisem que são exibidas ao público. A riqueza de detalhes, às vezes, é notável. Mas as fotografias, geralmente, implicam a escolha de um ângulo. E esse foi o caso...

Figura 3: Feira das ideias. Colégio Chafic Cury. Rio Azul/PR.

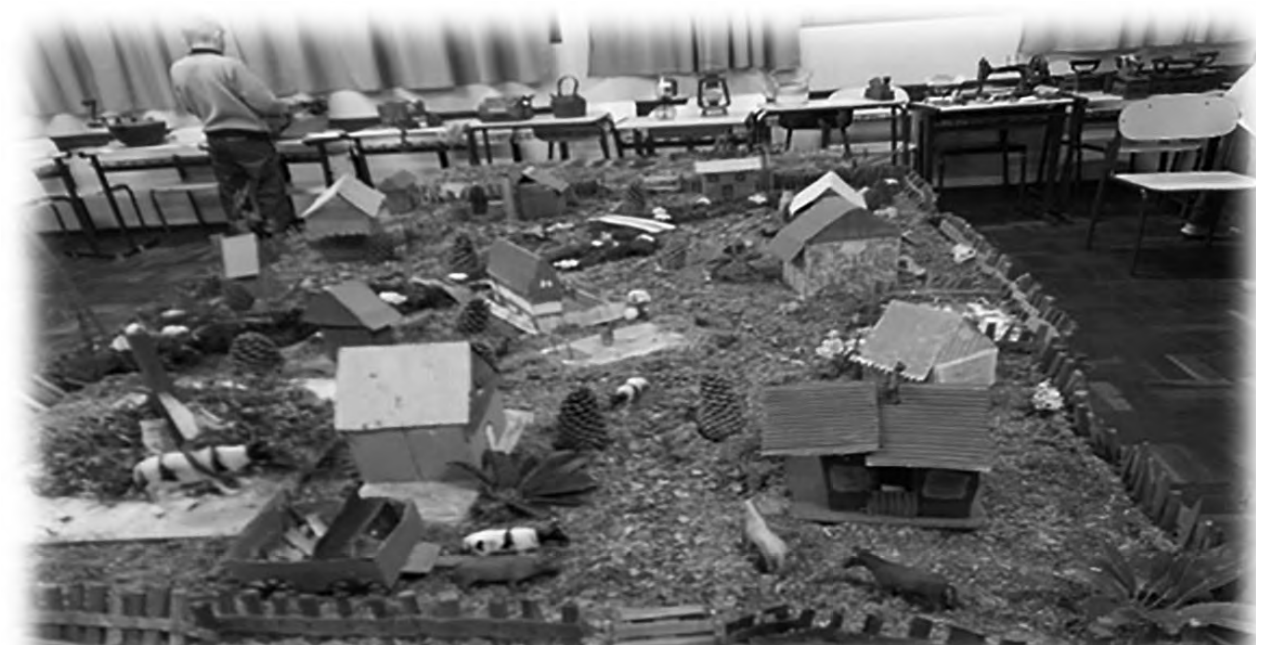

Autor: Equipe Lapef (Laboratório dos Povos Eslavos e Faxinalenses/Unicentro, 2014. Acervo: Lapef/I. 
A vinculação da imagem ao croqui e ao perfil esquemático, anteriormente discutidos, é devida à escolha da imagem dentre as outras da mesma maquete existentes no acervo de que faz parte, o do Lapef. Vale notar que o corte fotográfico criou uma espacialidade em que o espectador, igualmente, se localiza fora da área de criar. Implica, mais uma vez que o faxinal começa na cerca e com a cerca. Podemos indicar, no entanto, pequena variação já presente no perfil esquemático: a área de plantar não é mais espaço vazio.

Talvez, a incisão seja ainda mais radical porque, como se vê, tal área foi totalmente excluída pelo fotógrafo. Na maquete, entretanto, ela ocupa um espaço diametralmente igual à área de criar, iniciando na cerca que passa atrás das últimas casas. Então, o fotógrafo impôs a perspectiva e nós o seguimos, pois poderíamos ter escolhido uma tomada do outro lado, foto que de fato existe no acervo citado.

Como a cerca comum repete-se, então, atravessando toda a extensão da imagem, poderíamos ver reafirmando-se a tese de Chang (1988) de que os faxinais, enquanto organizações consolidadas, começam com a introdução de tal artefato. Ocorre que a fotografia não é a maquete, porque a primeira foi feita por estudantes pesquisadores do tema faxinais e a segunda por alunos e professores moradores de localidades organizadas em forma de faxinal. Aí deve residir alguma diferença, pois tal prerrogativa pode implicar outras variações de sentido, haja vista que os acadêmicos tendem a reproduzir a visão da academia, pelo menos em parte.
Tomemos o mata-burro, figura emblemática relativa ao acesso das pessoas e animais à área de criar, como referência. No croqui, as terras de plantar (que nem aparecem) se situariam na parte da frente; no perfil esquemático, localizam-se nas laterais; na fotografia da maquete, estão situadas na parte dos fundos. Isso pode significar que os faxinalenses estão ou se pensam desde o interior do criadouro, que se veem voltados de frente para as áreas que não são organizadas em forma de faxinal: as propriedades rurais particulares e os espaços urbanos.

Diferentemente do croqui, o perfil esquemático e a fotografia/maquete enfocam o mata-burro, ou seja, as entradas do faxinal. O detalhe pode parecer periférico, mas evidencia o dado de que, na representação em forma de croqui, o caminho que conduz ao interior está ao longe e não é acessível ao observador se, por acaso, ele quiser entrar no criadouro. De fato, as entradas e saídas do faxinal são protegidas por porteiras e cancelas ou por uma espécie de pequenas pontes, construídas sobre valos escavados especialmente para tal fim. Os artefatos que cobrem esses sulcos, de em média um metro de fundura por um e meio de largura, são feitos intercalando-se uma prancha de madeira ou barra de ferro e um vão. Assim, as pessoas, os automóveis e as máquinas agrícolas podem transitar sem a necessidade de se abrir porteiras, enquanto que os animais os evitam por temer quebrar suas pernas. Para que o gado e os animais de tração e montaria possam trafegar, constrói-se uma cancela ao lado com piso não vazado. 
O mata-burro pode ser considerado como uma marca da introdução dos veículos motorizados e da agricultura mecanizada nos faxinais, que, em termos do estado do Paraná, iniciou na década de 1970. Uma cancela, portanto, poderia representar melhor a etapa anterior a ser chamada de faxinal da agricultura de subsistência. Então, no caso das maquetes, o mata-burros está presente, mas sintomático ainda, não se representou a cancela lateral que, como veremos mais a frente, é destacada em alguns desenhos e pinturas.

Dizemos sintomático, pois é bem lógico que a cancela lateral não tenha significa- do relevante para os alunos da educação básica moradores de faxinais no ano de 2014, geração acostumada ao transporte em veículos e em outros implementos motorizados. Com efeito, os ritmos são outros... Saltar de um veículo para abrir uma cancela, tarefa destinada via de regra aos mais jovens, não será muito atrativo no tempo do controle eletrônico. Por esse motivo, o mata-burro representará uma comodidade significativa que aparece nesta maquete organizada por alunos moradores dos faxinais dos Galvão e da Ribeira (Imbituva-PR).

Figura 4: Feira da ciência - Colégio Alcides Munhoz. Imbituva-PR.

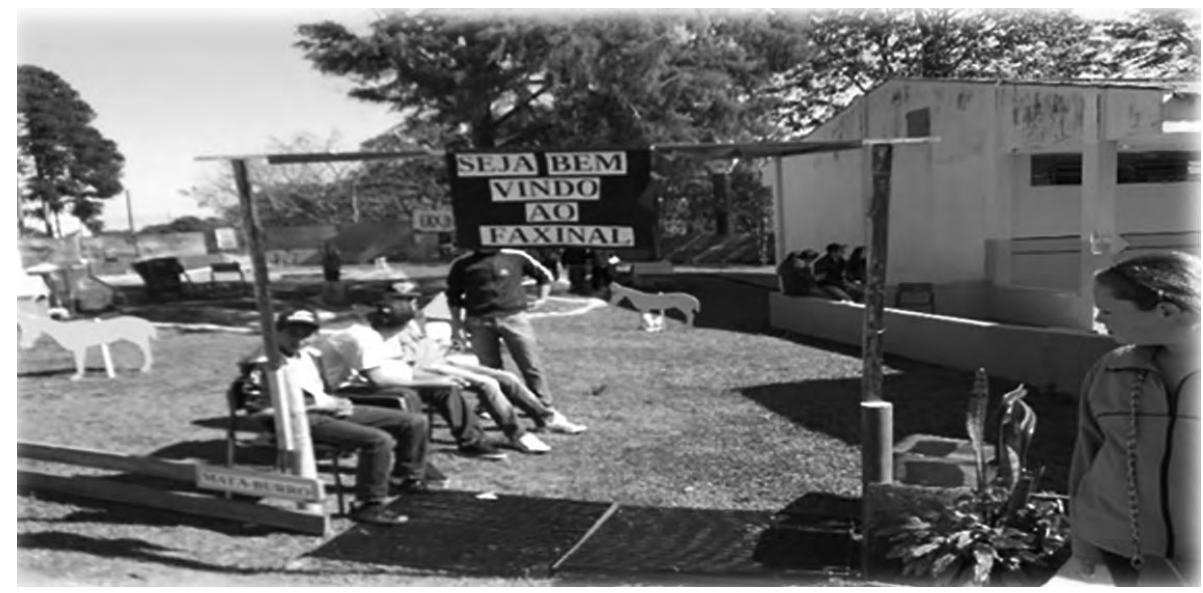

Autor: Equipe Lapef//, 2014. Acervo: Lapef/l.

Atentemos para a tomada e o corte fotográfico, comentados anteriormente, são de alunos de graduação. $\mathrm{O}$ espectador está na entrada que foi engalanada com portal e fitas vermelhas, com um cartaz de boas-vindas aos visitantes, o qual está virado para fora. O escrito indica que os visitantes vêm de um espaço externo e que os produtores da maquete se situam no interior do criadouro.
Como as dimensões do cenário permitem, aqueles que chegam podem transpor o mata-burro (proporcionalmente exagerado) e passear pelo interior do espaço reproduzido, o que implica a descoberta de modalidades de maquetes e escalas de representação tridimensional dos faxinais.

Tal modulação na espacialidade e variação escalar modifica as perspectivas de 
observação das maquetes. Numa delas (Figura 3), os expectadores permaneciam do lado de fora, estáticos, para fruir da representação. Noutra (Figura 4), eles caminhavam e circulavam pelo interior do espaço. Assim, as maquetes podem ser associadas a esquemas narrativos que, por sua vez, são vinculados aos tipos arcaicos benjaminianos: aquelas que possibilitam aos espectadores caminharem pelo seu interior, ao saber das terras distantes, dos marujos e migrantes, que se movem na espacialidade, no deslocamento e assim por diante ; e as elaboradas em escala reduzida, ao saber, às tradições do passado, ao conhecimento do camponês, da tradição do trabalhador sedentário. Nessas maquetes, o espectador não ingressa no interior da representação, de modo que a experiência de transitar pelas entradas, redes de caminhos e "carreirinhos" é transmitida por quem confeccionou-as. Esses são conhecedores da tradição, mas não por um contato passageiro, e, sim, por meio da vivência.

Na maquete ampliada, o saber do espaço e do tempo presente é partilhado qua- se que imediatamente, porque o espectador caminha no objeto, assim como alguém que realiza uma viagem a uma terra distante. Esse pode falar das coisas que viu por ter se deslocado entre facetas que visualizou, assim como um consumidor que se desloca entre mercadorias numa feira ou num supermercado. Na maquete, ao contrário, é o olhar que se desloca, que transita e que captura.

A recorrência à maquete, ao desenho e à pintura nos permite pensar, com Valter Benjamin e Michel de Certeau, o deslocamento dos corpos e dos olhares como atos de consumo, que longe de serem passivos ou mecânicos, implicam reelaborações, "fabricações" por parte desses moradores dos faxinais. Ainda que seja no âmbito do ensino formal detecta-se um trabalho que nos permite falar em espaço praticado, evidenciando-se também em atividades feitas pelos faxinalenses fora do espaço da educação formal. Podemos ilustrar isso a partir de um registro fotográfico de 2005, uma tomada de quadro para mística, montado durante a realização do já referido $1^{\circ}$ Encontro dos Povos dos Faxinais.

Figura 5: Quadro de mística do $1^{\circ}$ Encontro dos Povos dos Faxinais.

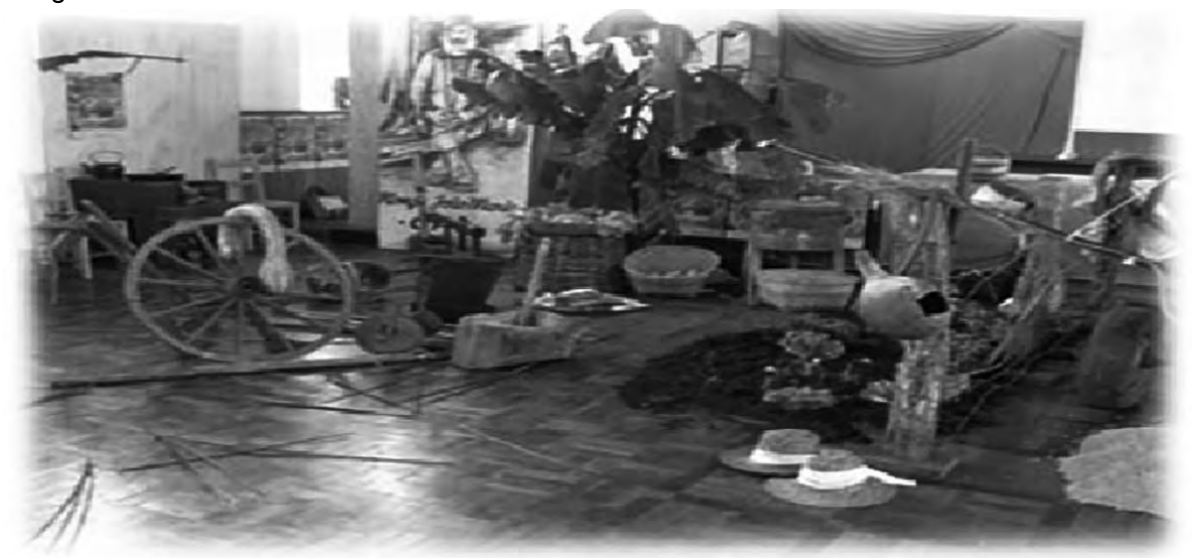

Fonte: Anais do $1^{\circ}$ encontro dos Povos dos Faxinais (2005). 
Nota-se, nessa montagem feita por faxinalenses, que a cerca coletiva foi estendida lateralmente e não em corte transversal como nas outras representações vistas até aqui. Não há indicação de mata-burros, nem a clássica divisão espacial - terras de plantar e terras de criar. Além do mais, uma horta com terra preta e verduras foi posta nas proximidades do cercado, como se fosse um marcador do espaço em que se desenvolvem as atividades agrícolas. As referências a animais limitam-se à roda de carroça e ao arado de tração animal. A maior parte dos implementos agrícolas e objetos de uso nas lavouras é de uma fase anterior à mecanização (a jorna, os balaios ou cestos, o pilão), mas a roda com pneu indica a presença das máquinas e veículos motorizados. O quadro da religiosidade popular é representação da figura do Monge do Contestado, São João Maria, e um par de chapéus representando, talvez, os faxinalenses.

A montagem feita pelos participantes do $1^{\circ}$ Encontro, como já afirmamos, é da escala que oportuniza e convida o observador a entrar no espaço e que caminhando, possa consumi-lo. Isso nos permite inferir que esse "jogo das dimensões" como que se converte numa "pequena trapaça" obrigando a quem quiser fazer registros fotográficos panorâmicos e gerais, bem como a quem desejar produzir textos com pretensão de objetividade, a se situarem fora do espaço, ou então, a se declararem como estranho, devido ao lugar que ocupam no ambiente da maquete. Nessa escala maior, confessa seu não pertencimento por ser convidado a ingressar no recinto construído.

Essa é, em certa medida, a leitura/ consumo que notamos em um desenho feito por Jonathan W. Bobato (13 anos) morador faxinal dos Galvão. O trabalho foi feito após uma exposição organizada por sua professora. Em seu desenho, o cercado permaneceu, cortando a imagem horizontalmente de lado a lado, mas a estrada principal, que desaparece no horizonte, interrompe-a no sentido vertical. Por esse artifício, a espacialidade tradicional é substituída por outra: o faxinal não é mais dividido em área de plantar e área de criar. Agora são quatro espaços.

Figura 6: llustração de aluno do Colégio Alcides Munhoz. Imbituva-PR.

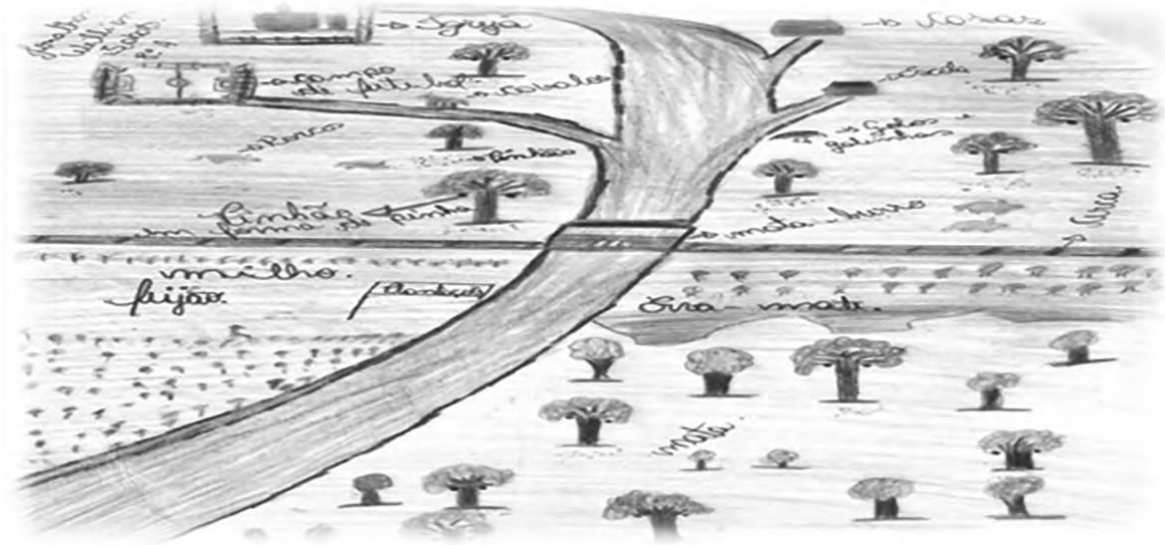

Autor: Equipe Lapef/l. 2015. Acervo: Lapef/l. 
O que normalmente seria o criadouro comum, torna-se espaço dividido: de um lado, a escola e a(s) casa(s); de outro, a igreja e o campo de futebol. Animais e pinheiros por toda parte. $\mathrm{O}$ espaço tradicionalmente definido, sobretudo pela academia, como área de plantar, dividido em dois: um para as plantações de milho e feijão; outro ocupado por ervais e matas. Nota-se que não se trata de ervais nativos porque as plantas de Ilex paraguariensis estão desenhadas com espaçamento e alinhamento regulares, denotando a ação humana no seu plantio.

As modificações mais interessantes, talvez, sejam a introdução da área de floresta nativa fora do criadouro e a simulação de uma área de religiosidade e lazer. Esses aspectos certamente introduzem uma perturbação no quadro esquemático produzido e reproduzido na perspectiva acadêmica. Evidencia, também, que a presença e circulação de conteúdos e imagens ensinados (por educadores, pregadores e vulgarizadores da visão dominante) ${ }^{9}$ não determina o que uma representação é para os seus usuários.

\section{Considerações finais}

Sem cair nos extremo das leituras contextuais tão costumeiras no campo da produção historiográfica contemporânea, podemos dizer, à guisa de conclusão, que em trabalhos acadêmicos, tanto escritos como imagéticos, destaca-se a constituição de certa espacialidade que, inclusive, torna-se proeminente no campo da historiografia, desde, pelo menos a década de 1990. Tal acento pode ser atribuido à falta de documentos escritos no âmbito das comunidades de po- vos tradicionais, o que não seria desmérito do historiador desde pelo menos a década de 1970, quando emerge a história do tempo presente. No início do século XXI, emergem as dicussões a respeito de uma antropologia da terrritorialidade para compreender-se os povos tradicionais no Brasil. De certa forma, consolidava-se e reiventava-se um ramo de produção escrita a respeito dos faxinais marcado pela tese de que o espaço de uso coletivo, plastificado pelo cercado comunitário, seria a marca distintiva dessa forma de organização camponesa já em presumível estado de desmantelamento. Tal caracterização foi reproduzida, em parte, na área de História por meio da simples divisão: terras de plantar, terras de criar. Mas o cercado, que demarcava o início hitórico, a chegada dos imigrantes poloneses tradicionalmente criadores de animais em cercados, se modifica para os processos de legalização formal de cada localidade faxinalense.

Nas produções acadêmicas, os desenhos representando os faxinais reproduzem a cerca coletiva, simulando uma separação entre o criadouro e o observador, o que, em certa medida, se repete nas maquetes e nos desenhos elaboradas por alunos da educação básica.

Mas ao invés de reprodução mecânica, os textos acadêmicos e os trabalhos escolares evidenciam-se como práticas de consumo criativas e reativas o modo certoniano e quando as maquetes são pensadas sob a noção benjeminiana do narrador. O jogo de escalas pode envolver os observadores e transeuntes. As telas, os desenhos e os quadros de mística elaborados por alunos moradores de faxinais, e por participantes de movimen- 
tos sociais podem situar quem se aproxima e indicar outras espacialidades que englobam aspectos mais ecológicos como a existência de florestas fora do criadouro comum.

\section{Abstract.}

In this article we discuss the construction of spatiality in the writing of the history of traditional peoples, especially the faxinalenses, having as sources texts and pictorial representations produced in the academic scope. Also, photographs of models, drawings and paintings, didactic material produced by elementary school students from the Irati/PR region. The time cut is from 1980 to 2015. These scenarios of mock-ups, academic texts and mystical parade (as well as photographic records) are products for consumption. The sketch, the schematic profile, and the academic texts analyzed here are the result of a consumption that, even within the rigid norms imposed by the scientific production system, can present something else, a modified or (re)signified reality against discourses and Processes of agricultural modernization.

Key-words: Faxinais. Images. Narratives. Spatialities.

\section{Resumen}

En este trabajo se analiza la construcción de la espacialidad en la historia escrita de los pueblos tradicionales, especialmente los faxinalenses, teniendo como fuentes textos y representaciones pictóricas producidas en el ámbito académi- co. También, fotografías de maquetas, dibujos y pinturas, material producido por los alumnos de escuelas de educación básica de la región de Irati/PR. El marco temporal es de 1980 a 2015. Estos modelos de escenarios de maquetas, textos académicos y 'cuadros' de místicas (así como registros fotográficos) son productos de consumo. El esbozo, el perfil esquemático y los textos académicos aquí analizados son el resultado de un consumo que, incluso dentro de las estrictas normas impuestas por el sistema de producción científica, consiguen presentar algo más, una realidad modificada o (re)significada frente a los discursos y a los procesos de modernización de la agricultura.

Palabras clave: Espacialidad. Faxinais. Imágenes. Narrativas.

\section{Notas}

1 Os trabalhos aqui utilizados foram fotografados, recolhidos ou doados ao Laboratório dos Povos Eslavos e Faxinalenses de Irati (Lapef/I) no âmbito do projeto do Observatório da Educação, Escola e ensino de história na região dos faxinais, entre os anos de 2013 e 2016, alcançando 27 municípios paranaenses em que existem ou existiram faxinais.

2 Expressão regional para designar passado.

3 Trabalhadores que juntavam-se nas tarefas das fazendas, mas com vínculo esporádico.

4 A tese de que os criadouros cercados surgiram por influência dos poloneses que cultivavam o hábito de criar os animais em áreas cercadas.

5 Assim, o criatório coletivo consiste num cercado em torno das habitações e da área de pastagem; na parte interior, que pode pertencer a um proprietário não morador do faxinal, ou a vários proprietários, são criados animais de várias espécies, tais como bovinos, equinos, caprinos, ovinos e suínos, além de vários tipos de aves domésticas. Soltos no cercado grande, esses animais alimentam-se da grama existente, de pequenos arbus- 
tos e dos frutos nativos tais como a gabiroba, a cereja, a pitanga e, principalmente, o pinhão, na época da safra das sementes de araucária.

6 Tese de Chang (1988) de que o costume polonês de criar os animais em áreas cercadas veio a consolidar o sistema de faxinal.

7 Nesse ponto, nos baseamos no texto de Orlandi (2009) para quem o discurso fundador " [...] não se apresenta como já definido, mas antes como uma categoria do analista a ser delimitada pelo próprio exercício da análise dos fatos que o constituem em relação à história de um país [...] funcionam como referência básica no imaginário constitutivo desse país".

8 Projeto do programa Observatório da Educação, iniciado em 2013 e com término previsto para 2017, e coordenado pelo professor José Adilçon Campigoto.

9 O agronegócio, a monocultura, o desmatamento e seus defensores e disseminadores de suas propagandas.

\section{Referências.}

BARRETO, Marcelo. Sistema Faxinal: uma forma de organização camponesa em desagregação no Centro-sul do Paraná. Terr@Plural, Ponta Grossa, v. 5, n. 2, p. 249-253, jul./dez. 2011.

BENJAMIN, Walter. Magia e técnica, arte e política: ensaios sobre Literatura e História da Cultura. Obras Escolhidas. Volume I. 7. ed. Tradução de Sérgio Paulo Rouanet. São Paulo: Brasiliense, 1994.

BOSI, Alfredo. O tempo e os tempos. In: NOVAES, Adauto (Org.). Tempo e História. São Paulo: Companhia das Letras, 1994. p. 19-32.

CERTEAU, Michel de. A invenção do cotidiano. Artes de fazer. Petrópolis: Vozes, 1994.

CHANG, Man Yu. Sistema Faxinal: uma forma de organização camponesa em desagregação no Centro-sul do Paraná. Londrina: IAPAR, 1988.

GOTTMANN, Jean. A evolução do conceito de território. Boletim Campineiro de Geografia, Campinas, v. 2, n. 3, p. 523-545, 2012.
LITTLE, Paul E. Territórios sociais e povos tradicionais no Brasil: por uma antropologia da territorialidade. Brasília, 2002. Disponível em: $<$ http://www.dan.unb.br/images/pdf/anuario antropologico/Separatas\%202002-2003/2002-2003_ paullittle.pdf $>$. Acesso em: 14 maio 2014.

LÖWEN SAHR, Cicilian Luiza. Faxinalenses: populações tradicionais no bioma da mata com araucária? ENCONTRO DOS POVOS DOS FAXINAIS, 1․ Anais... 2005, p. 53-62.

NERONE, Maria M. Terras de plantar, terras de criar - Sistema Faxinal: Rebouças (1950-1997). Assis, 2000. Tese (Doutorado em História). Departamento de História da Universidade Estadual Paulista, 2000.

ORLANDI, Eni Puccinelli. Análise de discurso: princípios \& procedimentos. 8. ed. Campinas: Pontes, 2009.

PRIORI, Ângelo. A modernização do campo e o êxodo rural. In: PRIORI, Ângelo et al. (Org.). A História do Paraná: séculos XIX e XX. Maringá: Eduem, 2012. p. 115-127. 